\title{
Ocular findings in a family with autosomal dominant retinitis pigmentosa and a frameshift mutation altering the carboxyl terminal sequence of rhodopsin
}

Eckart Apfelstedt-Sylla, Markus Kunisch, Monika Horn, Klaus Rüther, Heinrich Gerding, Andreas Gal, Eberhart Zrenner

\section{Department of Pathophysiology of Vision and \\ Neuroophthalmology, University Eye Hospital, Tübingen, Germany E Apfelstedt-Sylla \\ K Rüther \\ E Zrenner}

Department of Human Genetics, Medical

University, Lübeck Germany

M Kunisch

M Horn

A Gal

University Eye Hospital, Müinster, Germany

H Gerding

Correspondence to:

Eckart Apfelstedt-Sylla, MD

University Eye Hospital,

Schleichstrasse 12, W-7400

Tübingen, Germany.

Accepted for publication 8 March 1993

Figure 1 Pedigree of an adRP family with $a$ deletion of $8 b p$ in the rhodopsin gene. Solid symbols are affected members, open symbols are unaffected members. Slashed symbols are

deceased members. Arrows indicate persons examined ophthalmologically.

Asterisks indicate members who underwent $D N A$ analysis.

II

III

\begin{abstract}
A family is described in which an 8 base pair deletion (nucleotides 5252-5259, codons 341343) of the rhodopsin gene cosegregates with autosomal dominant retinitis pigmentosa (adRP). The deletion results in a shift in the reading frame, causing a rhodopsin molecule extended by one residue and substantially altered at the carboxyl terminus. Phenotypic expression is relatively mild. In affected members, night blindness did not occur before the age of 16, and late onset of visual field loss was consistently reported. Even older individuals ( 59 and 76 years) had preserved central islands in the visual field; a younger female patient had normal visual fields until the age of 34. ERG and psychophysical tests showed well preserved cone function at stages of virtually abolished rod function. Phenotypic differences and similarities between this form of adRP and others associated with mutations at the carboxyl terminus of the rhodopsin molecule are discussed. The cause of RP by mutations in this region remains to be clarified. (Brf Ophthalmol 1993; 77: 495-501)
\end{abstract}

In a subset of families with autosomal dominant retinitis pigmentosa (adRP), a variety of mutations in the gene encoding rhodopsin have been shown to cosegregate with clinical symptoms, ${ }^{1-5}$ and are therefore looked upon as the primary cause of the disease. Rhodopsin mutations are found in about one quarter of adRP families. ${ }^{25}$ The vast majority are point mutations, and only two inframe deletions of the rhodopsin gene have been reported. ${ }^{1}$ In addition, only few of the mutations found are located in the cytoplasmic domain of the rhodopsin molecule or its carboxyl terminal end, respectively. ${ }^{1-35}$ By screening European adRP families for the presence of rhodopsin mutations, two deletions at the c (carboxyl) terminal end of the rhodopsin molecule resulting in a shift of the reading frame were identified in two families. ${ }^{6}$ Here we report on the clinical findings in one of the families that displays a deletion of 8 base pairs (bp) spanning codons 341-343 (nucleotides 5252-5259) of the rhodopsin gene. Because of this frameshift deletion, the $c$ terminal end of rhodopsin is radically altered; nine 'new' amino acids appear. We were interested to determine the clinical phenotype of this mutation by electrophysiological and psychophysical testing of patients, as distinct rhodopsin mutations at the $c$ terminal end reported thus far show a wide range of symptoms. ${ }^{7-10}$ The reason for this variety is not yet known. Detailed clinical assessment of affected persons, however, may help to improve the understanding of disease expression in patients with different rhodopsin mutations.

\section{Patients and methods}

The German adRP family presented here (see pedigree in Fig 1) was included in the screening programme for rhodopsin mutations at the department of human genetics of the Medical University Lübeck. Screening for mutations was carried out by restriction digestion, heteroduplex analysis, single strand conformation polymorphism (SSCP) analysis, and genomic sequencing following polymerase chain reaction (PCR) amplification of the five rhodopsin exons, as previously described. ${ }^{611}$

Four affected members were seen for clinical investigation by the authors (EA-S, HG, or EZ respectively), whereas histories from another two affected members were obtained by questioning relatives.

For each proband, an extended questionnaire was completed with respect to age at onset of 


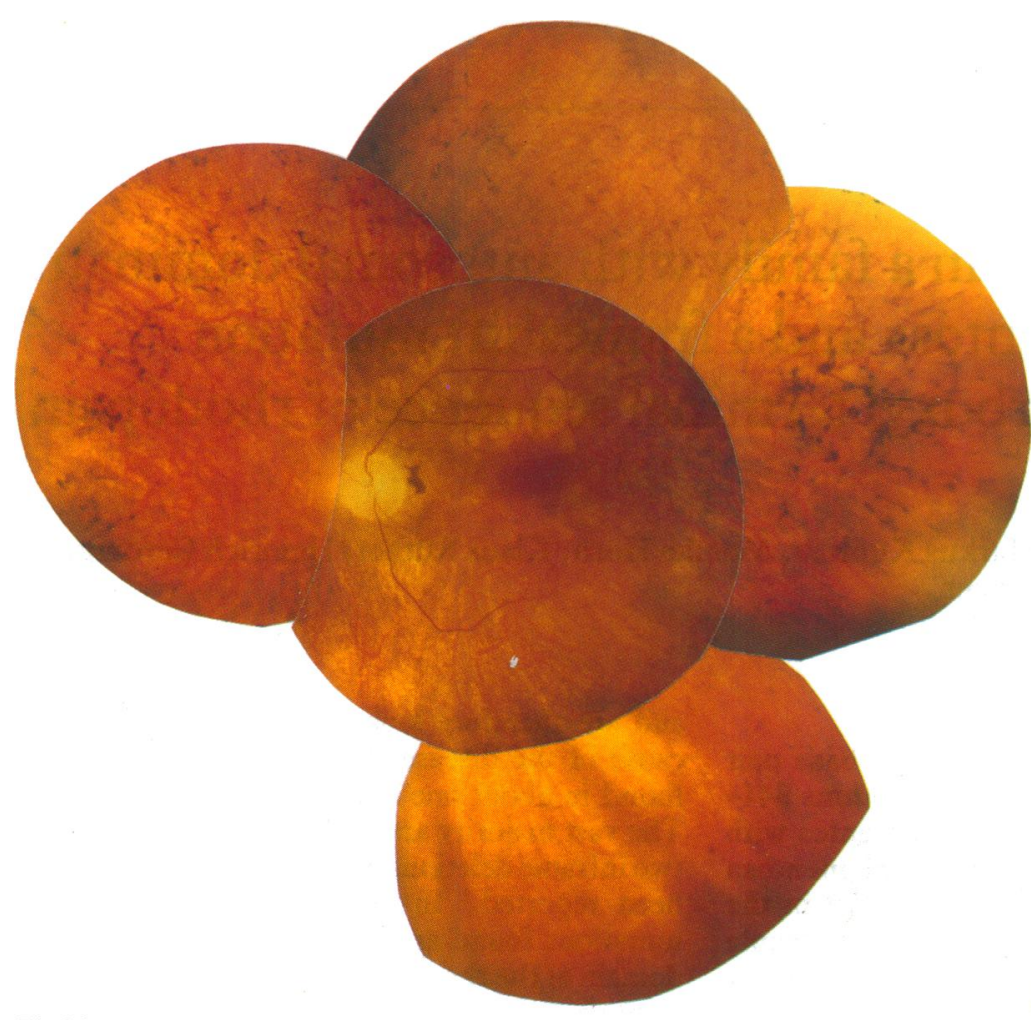

Fig $2 A$

Figure 2 Fundus photographs from patients with an 8 base pair deletion of the rhodopsin gene. (A) 76-year-old patient II-8, showing optic atrophy, severe retinal vessel attenuation and choroid atrophy outside the macular area. There is diffuse loss of retinal pigment epithelium and mid-peripheral bone spicule pigmentation. (B) 34-year-old patient III-2, showing multiple yellowish spots in the retinal pigment epithelium layer. Vessels are only mildly attenuated; there are no bone spicule pigmentations.

night blindness, side vision impairment, glare sensitivity, and reading difficulties. Ophthalmic examination included distance visual acuities, slit-lamp examination with respect to lens opacities and vitreous changes, direct and indirect funduscopy, fundus photography, colour vision test, kinetic perimetry, electroretinography, and, in one patient, fluorescein angiography, dark adaptation, and two colour dark adapted threshold perimetry.

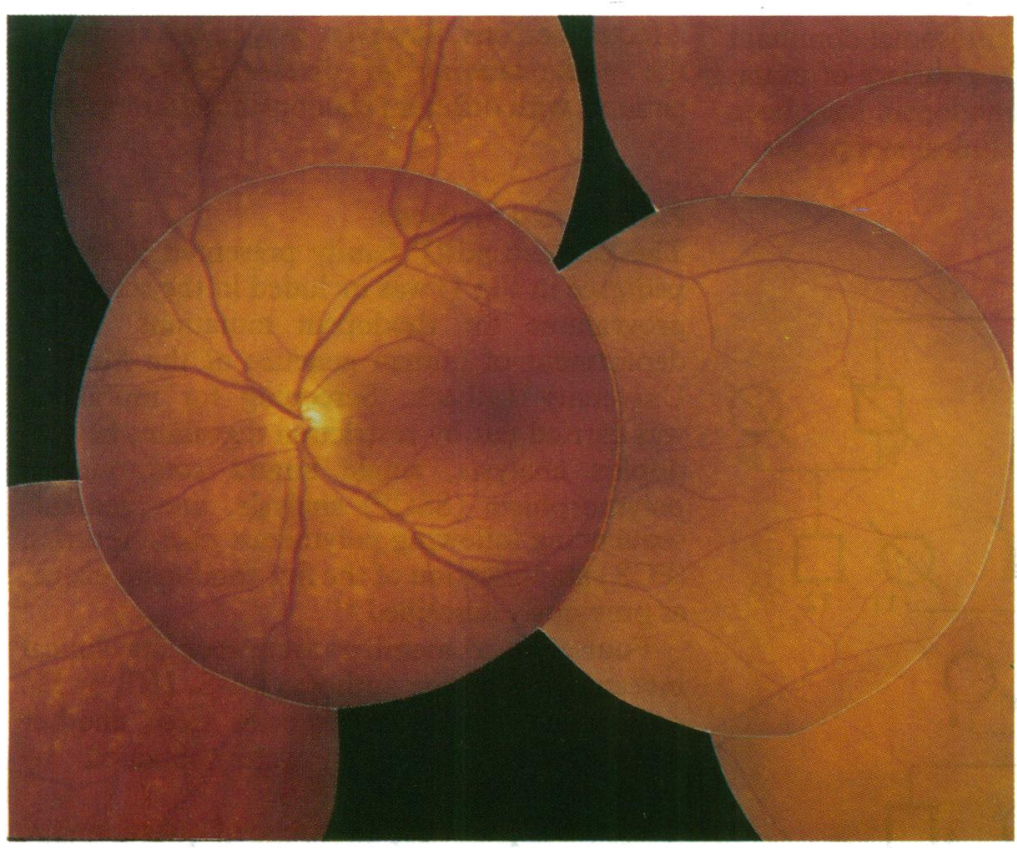

Fig $2 B$
On slit-lamp examination lens opacities were estimated following the classification of Fishman. ${ }^{12}$ Colour vision was examined with the desaturated Lanthony Panel D 15 test. Kinetic visual fields were obtained with a Goldmann perimeter or a Tübinger perimeter, using $30^{\prime}$ and $10^{\prime}$ white test spots of $200 \mathrm{~cd} \mathrm{~m}^{-2}$ on a background of $3 \cdot 3 \mathrm{~cd} \mathrm{~m}^{-2}$. Stimuli were moved from non-seeing to seeing areas. Dark adaptation was tested over a period of $\mathbf{4 0}$ minutes after dilating the pupils with tropicamide $(0.5 \%)$ and after a preadaptation period of 10 minutes to a ganzfeld of $890 \mathrm{~cd} \mathrm{~m}^{-2}$. The dark adaptation curve was obtained at $20^{\circ}$ eccentricity on the horizontal meridian of one eye, determining the luminance necessary for the detection of a 106' white stimulus (stimulus duration, $500 \mathrm{~ms}$ ) in a Tübinger perimeter, using $0 \cdot 1 \mathrm{log}$ increments. Thresholds were expressed in terms of attenuation relative to maximum luminance (272 $\mathrm{cd} \mathrm{m}^{-2}$ ). Subsequently dark adapted two colour threshold perimetry was performed along the horizontal meridian with a $500 \mathrm{~nm}$ and a $656 \mathrm{~nm}$ 106 ' stimulus, following the method of Massof and Finkelstein. ${ }^{13}$ Thresholds were measured at the fovea at $2^{\circ}, 6^{\circ}, 10^{\circ}$, and then in $10^{\circ}$ steps towards the nasal and temporal border. After 30 minutes of dark adaptation, full field ERGs were recorded from both eyes with a Nicolet Compact Four with ganzfeld controller (Nicolet Biomedical Instruments, Madison, Wisconsin, USA), and DTL electrodes ${ }^{14}$ according to the international ERG standard. ${ }^{15}$ ERG responses were amplified, bandpass filtered, and computer averaged. An artefact rejection was applied to eliminate disturbances by blinking reflexes. Rod responses were elicited by $0.5 \mathrm{~Hz}$ white stimuli (duration of $100 \mu \mathrm{s}$ ). A standard flash of 2.5 $\mathrm{cd} \mathrm{m}^{-2}$ intensity was attenuated by $2 \cdot 5 \log$ units with a Kodak Wratten neutral density filter. A mixed rod/cone response was obtained with a $0.2 \mathrm{~Hz}$ white flash at standard flash intensity. In cases of non-detectable responses, we presented a $4.5 \mathrm{~Hz}$ stimulus with maximum luminance and averaged 200 recordings in order to detect small remnant responses. Oscillatory potentials were recorded by using a standard flash and cut off filters at 100 and $250 \mathrm{~Hz}$. Photopic responses were obtained after 10 minutes of light adaptation to a ganzfeld dome background illumination of $30 \mathrm{~cd} \mathrm{~m}^{-2}$ with white $30 \mathrm{~Hz}$ flicker stimuli and white single flashes at standard flash intensity. Responses to red single flashes were obtained with a Kodak Wratten W 25 filter.

\section{Results}

REPORT OF CASES

Individual I-1

No medical records were available from this man. He was reported to have severely impaired visual fields and visual acuity from his mid 50s.

\section{Individual I-4}

This woman died at the age of 61 . She appeared to be completely night blind, and to have constricted visual fields and reduced visual acuity in 


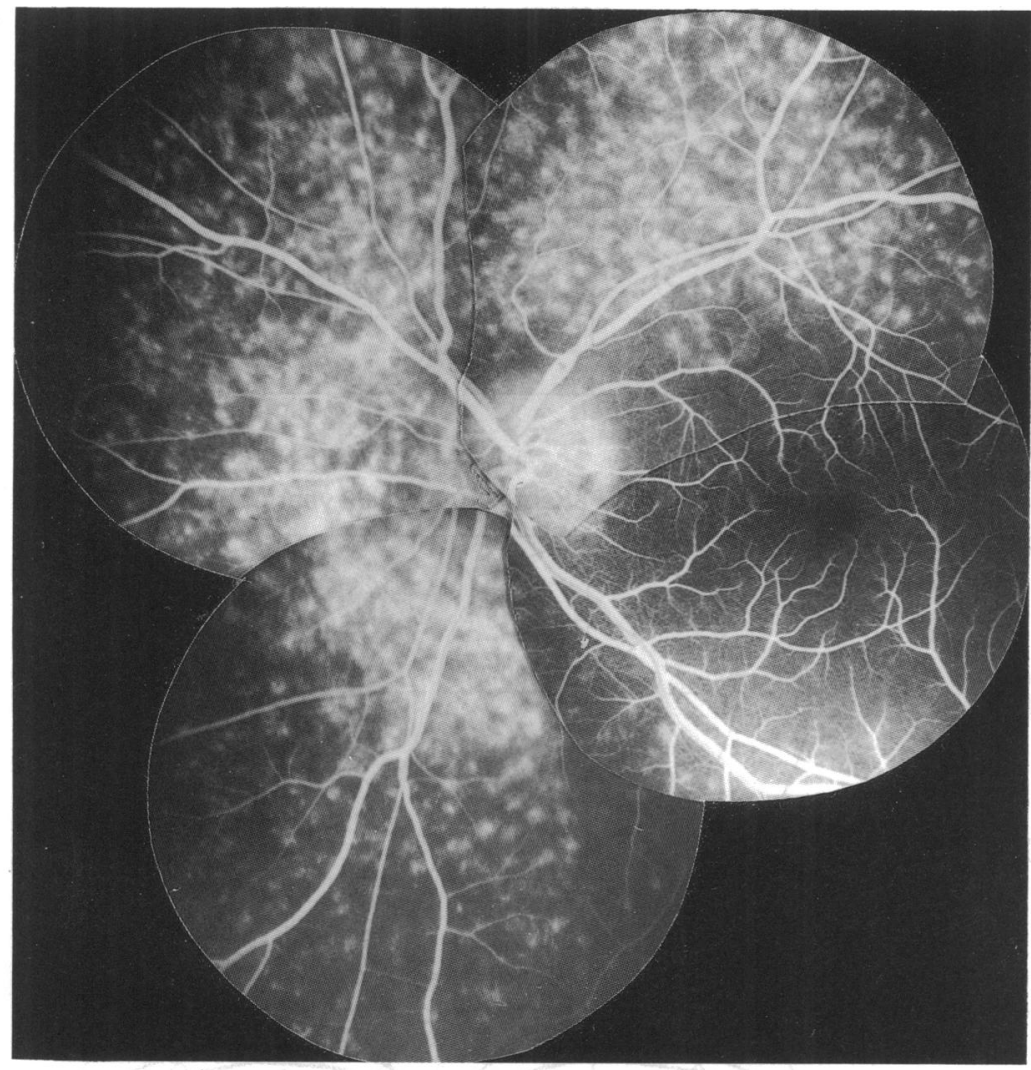

Fig $2 C$

Figure 2 (C) Fluorescein angiogram of III-2. There are multiple hyperfluorescent granules surrounding the optic disc and the macula. (D) Fundus of 4-year-old patient IV-1. There are only minimal findings of nerve fibre layer dropout superior to the optic disc. her last years. Medical records were not available.

\section{Proband II-8}

This 76-year-old man first noted difficulties with night vision at the beginning of his third decade of life and complained of increased glare sensitivity from about age 55 . He stated that side vision impairment did not become noticeable until the age of 66, when the diagnosis of RP was

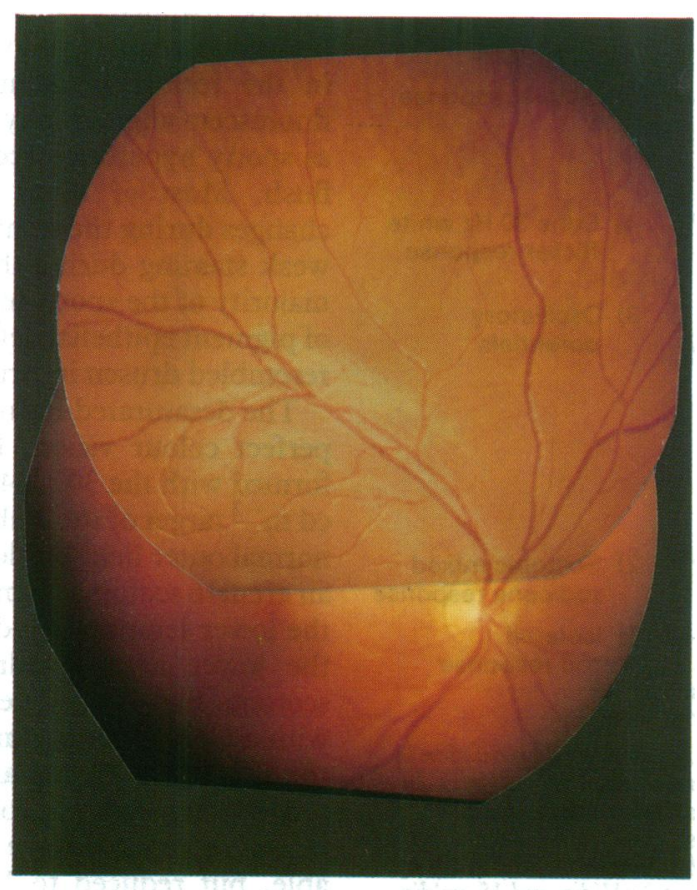

Fig $2 D$ established. Central vision and reading acuity had markedly deteriorated in the last year. On examination, the patient had a visual acuity of $20 / 60$ in each eye. The refractive error was $+2 \cdot 5$ $\mathrm{sph}-1 \mathrm{cyl}$ axis $35^{\circ}$ in the right eye and $+3.0 \mathrm{sph}$ -1 cyl axis $135^{\circ}$ in the left eye. Slit-lamp examination revealed a small posterior subcapsular cataract in both eyes, as well as trace of cells and a posterior detachment of the vitreous.

On funduscopy (Fig 2A), he had optic atrophy and severe vessel attenuation in both eyes. There was an overall retinal pigment epithelium loss sparing only the fovea, some apparent choroidal sclerosis in the perimacular region as well as in the midperiphery, and typical bone spicule pigmentation scattered in all quadrants of the retina. Both maculae appeared to be atrophic. Colour vision testing revealed a tritan defect in both eyes. Visual fields (see Fig 3 ) were constricted to about $3^{\circ}$ for the $30^{\prime} / 314 \mathrm{~cd} \mathrm{~m}^{-2}$ and about $2^{\circ}$ for the $10^{\prime} / 314 \mathrm{~cd} \mathrm{~m}^{-2}$ target of the Tübingen perimeter, respectively. In contrast Goldmann perimetry performed at the age of 68 had shown a central field of $6-8^{\circ}$ around fixation, and preserved temporal islands for the III $/ 4 \mathrm{e}$ stimulus in both eyes. The rod and the cone ERG were non-recordable.

\section{Proband II-10}

$\mathrm{He}$ had noted poor night vision from the age of 45 , and restricted visual fields from about 10 years later. He was initially diagnosed as having $\mathrm{RP}$ at the age of 59. On this ocular examination, visual acuity was correctable to $20 / 60$ right eye with a $-1 \mathrm{D}$ sphere, and 20/100 left eye with a $-1.5 \mathrm{D}$ sphere. Slit-lamp findings were normal in each eye. The fundus examination showed optic atrophy and marked vessel attenuation. There was bone spicule pigmentation all over the mid-peripheral parts of the retina. The changes were bilaterally symmetrical. In Goldmann perimetry (Fig 3), the patient's visual fields were constricted in both eyes, to $20^{\circ}$ around fixation for the IV/4e target and about $10^{\circ}$ for the $I / 4 \mathrm{e}$ target, respectively. Retesting 3 years later showed central islands of $10^{\circ}$ and $5^{\circ}$ around fixation, respectively. Scotopic and photopic ERG responses had already been non-detectable at his first visit.

\section{Proband III-2}

In the 34-year-old daughter of II-8, a strabismus of the right eye had been detected at the age of 2 . She first recognised problems with night vision at the age of 16, and, only recently, a slight increase in glare sensitivity. She was not conscious of any side vision or visual acuity impairment. At the age of 30 an abnormal ERG had led to the diagnosis of RP.

On examination, visual acuity was 20/25 right eye and 20/20 left eye. The refractive error was $-0.5 \mathrm{cyl}$ axis $35^{\circ}$ right eye and -0.5 cyl axis $0^{\circ}$ left eye. There was a slight esotropia of the right eye. Slit-lamp examination did not show lens opacities or vitreous changes.

On funduscopy (Fig 2B), the optic discs appeared normal, and retinal arterioles were only moderately attenuated. The maculae showed 
Patient II-8 (age, 68 years)

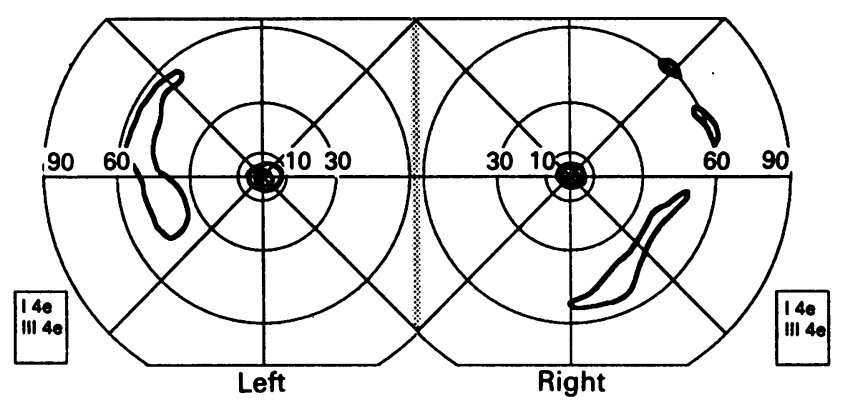

Patient II-10 (age, 59 years)

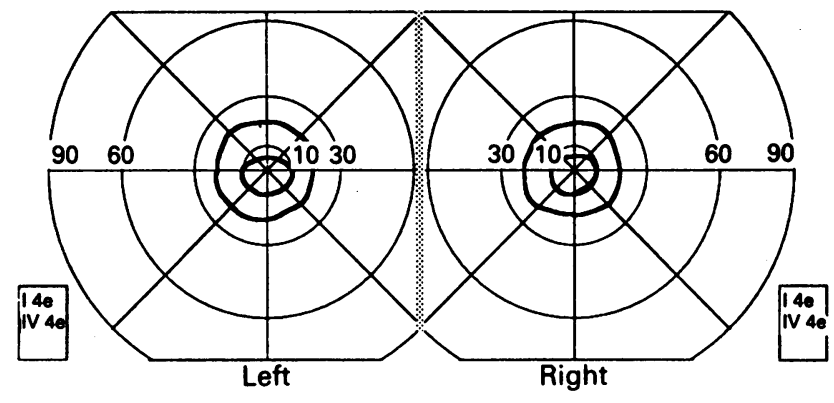

Patient III-2 (age, 29 years)

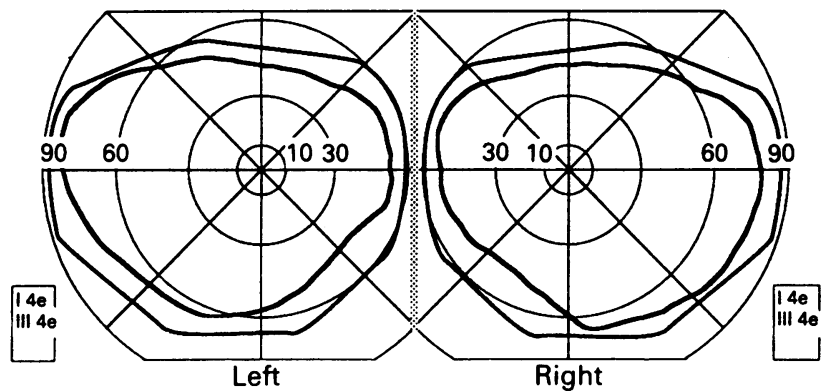

Patient II-8 (age, 76 years)

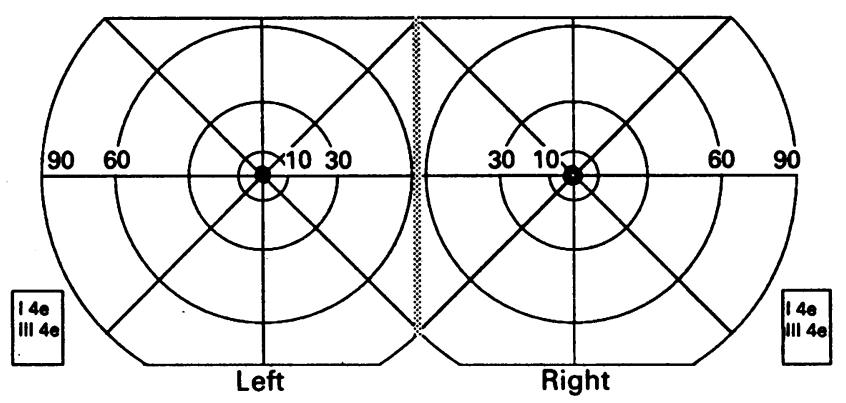

Patient II-10 (age, 62 years)

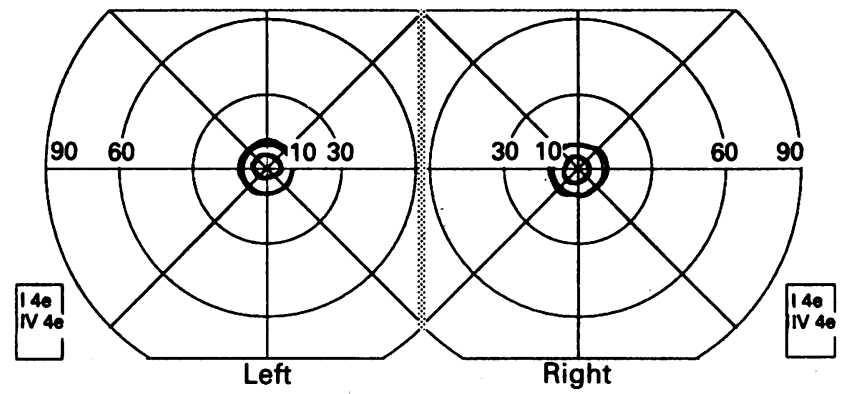

Patient III-2 (age, 34 years)

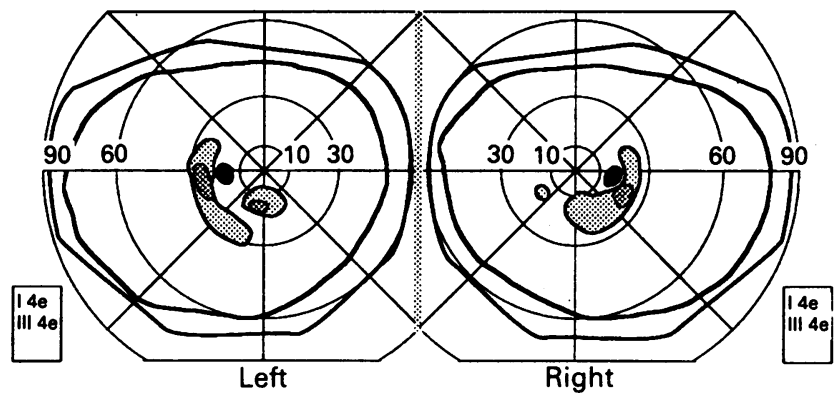

Figure 3 Consecutive kinetic visual fields of patients II-8, II-10, and III-2 with an 8 bp deletion in the rhodopsin gene. For convenience, targets $30^{\prime}-200$ $c d \mathrm{~m}^{-2}$ and $10^{\prime}-200 \mathrm{~cd} \mathrm{~m}^{-2}$ of the Tübinger perimeter are referred to as targets III/4e and I/4e, since they are equivalent to the test spots of our Goldmann perimeter.

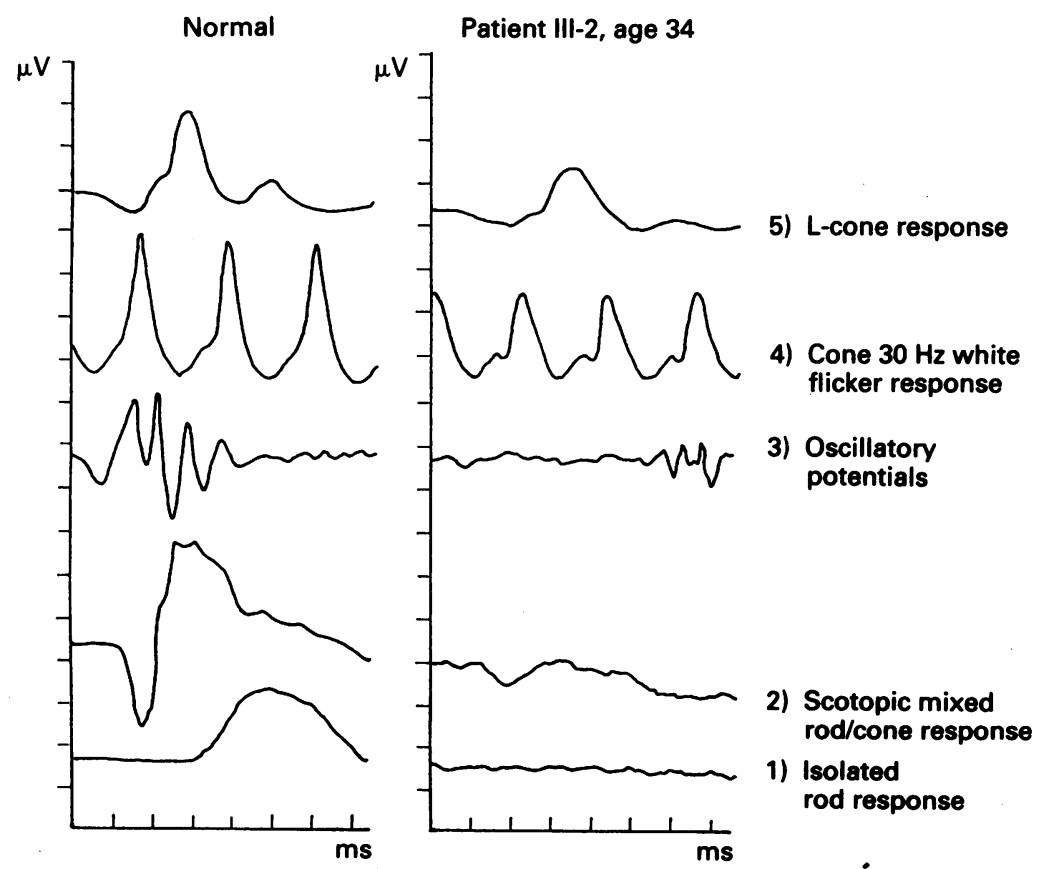

Figure 4 ERG rod and cone responses in individual III-2, age 34 , with an 8 bp deletion in the rhodopsin gene (right) and a normal subject approximating normal mean values (left). In III-2, the rod b wave to dim white flashes is non-detectable, the scotopic mixed rod/cone response and oscillatory potentials are severely reduced. In contrast, cone amplitudes are in the low normal range; cone implicit times are slightly increased. Calibrations are: $120 \mu V / d i v$ and $20 \mathrm{~ms} /$ div in traces 1) and 2); $25 \mu \mathrm{VIdiv}$ and $10 \mathrm{~ms} /$ div in trace 3); $50 \mu \mathrm{V} / \mathrm{div}$ and $15 \mathrm{~ms} / \mathrm{div}$ in trace 4); and $50 \mu$ VIdiv and $10 \mathrm{~ms} /$ div in trace 5). only some wrinkling of the inner limiting membrane. Bone spicule pigmentations were virtually absent. In the perimacular as well as in the peripapillary and midperipheral regions, multiple irregular yellowish spots were present in the retinal pigment epithelium layer. On fluorescein angiography (Fig 2C), they appeared as spotty hyperfluorescences with the choroidal flush. Most of them did not show marked changes during the transit, while some showed a weak staining during the late phases. Thus the majority of the spotty lesions were characteristic of pigment epithelial defects, while some of them resembled drusen in Bruch's membrane.

The desaturated Farnsworth D15 test showed perfect colour vision. Perimetry (Fig 3), performed with the $30^{\prime} / 314 \mathrm{~cd} \mathrm{~m}^{-2}$ and the $10^{\prime} / 314$ $\mathrm{cd} \mathrm{m}^{-2}$ target of the Tübinger perimeter showed normal outer field borders, but the beginning of an arcuate scotoma from 10 to $30^{\circ}$ eccentricity. in the lower temporal, and, to a smaller extent, in the lower nasal quadrants of each eye. No scotoma had been detected on a previous test with a Goldmann perimeter at the age of 29 . In the ERG (Fig 4), the amplitude of the isolated rod b wave was approximately zero. Scotopic mixed rod/cone b wave amplitudes were detectable, but reduced to $15-20 \%$ of mean normal amplitudes. Oscillatory potentials were barely 
Figure 5 Dark adaptometry at $20^{\circ}$ nasally with a 106' white stimulus in normal observers (shaded area, $\pm 2 S D)$ and patient III-2(solid line)

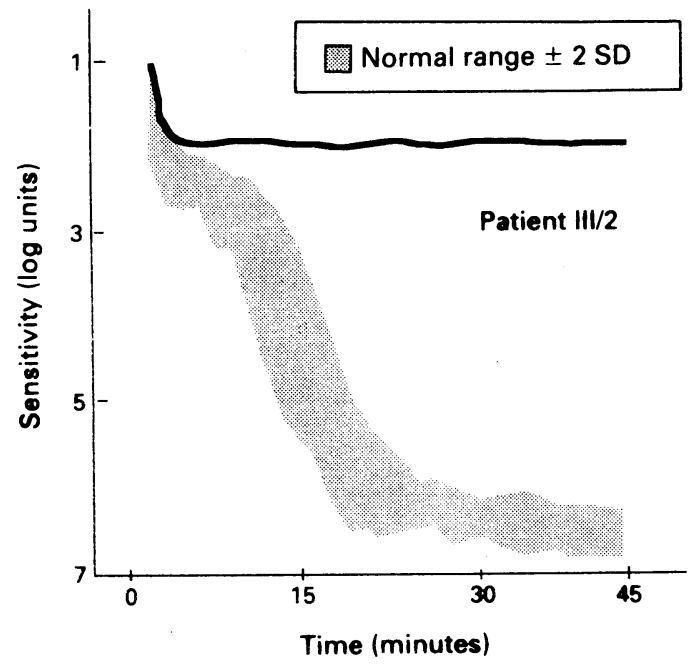

recordable. In contrast, all light adapted cone amplitudes were still in the low normal range, with slightly increased implicit times.
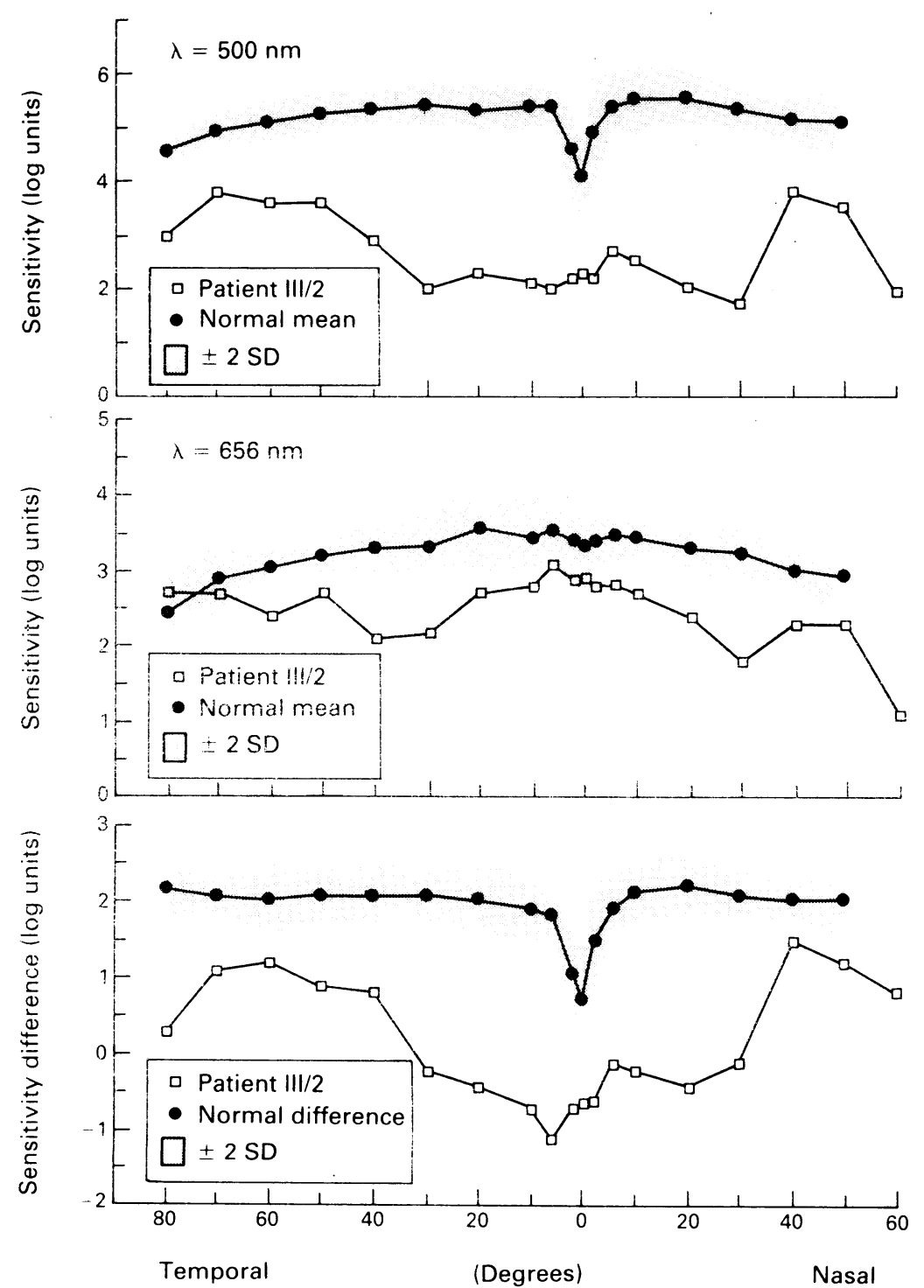

Figure 6 Dark adapted two colour threshold profiles along the horizontal meridian in normal observers (upper curve, mean (2SD)) and patient III-2 with an 8 base pair deletion in the rhodopsin gene (lower curve). Top, sensitivities to $500 \mathrm{~nm}$; middle, sensitivities to $656 \mathrm{~nm}$; bottom, sensitivity differences between the two stimuli. In case III-2, rods detect the $500 \mathrm{~nm}$ stimulus in the far periphery. In all other regions, cones detect both stimuli, indicated by $a$ sensitivity difference near zero.
The dark adaptation curve (Fig 5), determined at $20^{\circ}$ nasally on the horizontal meridian, was monophasic, revealing absence of rod function, impaired cone function, and a final threshold elevation of $4.5 \mathrm{log}$ units.

On two colour (500 nm and $656 \mathrm{~nm}$ ) dark adapted static perimetry along the horizontal meridian (Fig 6), rod sensitivity as determined by the blue-green stimulus was reduced in all regions. Threshold elevation, however, varied, being most prominent within $30^{\circ}$ around fixation, where cones detected the $500 \mathrm{~nm}$ target. At greater eccentricities, thresholds were mediated by rods.

Cone sensitivity was considerably less reduced at all loci measured. Thresholds for $656 \mathrm{~nm}$ stimuli were all detected by cones. In the macular area, as well as in the far periphery, sensitivity was within the low normal range. Maximum sensitivity loss was between 30 and $40^{\circ}$ eccentricity.

\section{Proband IV-I}

The 4-year-old son of III-1 had no noticeable visual impairment at the time of our evaluation. Visual acuity in the Sheridan Gardiner test was $6 / 6$ each eye. Colour vision was normal. Funduscopy (Fig 2D) showed no alterations besides a broadened perimacular reflex of the inner limiting membrane and a nerve fibre layer dropout superior to the optic discs. Consent for ERG testing was not given by the parents.

\section{Person III-4}

This person had no visual complaints and did not show any signs of retinitis pigmentosa on an extended ocular examination (data not shown).

A summary of the findings in patients is provided in Table 1.

\section{DNA ANALYSIS}

In patients II-8, III-2, and IV-1, heteroduplex analysis of PCR amplified rhodopsin exon 5 revealed two bands of approximately similar intensity after ethidium bromide staining (not shown). The upper band corresponded to a fragment of the expected size $(219 \mathrm{bp})$, and the lower one to a fragment being smaller by about $10 \mathrm{bp}$. The ron affected relative studied (III-4) showed only one (homoduplex) band. Likewise, altered electrophoretic mobility of PCR fragments resulting in various band shifts was observed in the patients' DNA by single strand conformation polymorphism (SSCP) analysis (Fig 7; for details of the method see Horn et al ${ }^{6}$ ). All these findings indicated a sequence change in exon 5 of the patients' rhodopsin gene. Indeed, direct sequencing of the PCR products from two patients revealed a deletion of $8 \mathrm{bp}$ (nucleotides 5252-5259 in codons 341-343) predicting a protein with significantly different amino acid composition from codon 341 onwards and an overall length of 349 residues owing to the mutation setting the normal stop signal out of frame (see Fig 8). The deletion could not be detected in another 150 unrelated adRP patients. 
Table 1 Ocular findings in patients with an 8 bp deletion in the rhodopsin gene

\begin{tabular}{|c|c|c|c|c|c|c|}
\hline $\begin{array}{l}\text { Patient, } \\
\text { age } \\
\text { (years) }\end{array}$ & Eye & $\begin{array}{l}\text { Visual } \\
\text { acuity }\end{array}$ & $\begin{array}{l}\text { Refractive } \\
\text { error }\end{array}$ & $\begin{array}{l}\text { Lens } \\
\text { PSC } \\
\text { (grade)* }^{\star}\end{array}$ & $\begin{array}{l}\text { Macula } \\
\text { (main finding) }\end{array}$ & $\begin{array}{l}\text { Peripheral bone } \\
\text { spicule pigment }\end{array}$ \\
\hline $\begin{array}{l}\text { II-8, } 76 \\
\text { II-10, } 59 \\
\text { III-2, } 34 \\
\text { IV-1, } 4\end{array}$ & $\begin{array}{l}\mathbf{R} \\
\mathbf{L} \\
\mathbf{R} \\
\mathbf{L} \\
\mathbf{R} \\
\mathbf{L} \\
\mathbf{R} \\
\mathbf{L}\end{array}$ & $\begin{array}{c}20 / 60 \\
20 / 60 \\
20 / 60 \\
.20 / 100 \\
20 / 25 \\
20 / 20 \\
6 / 6 \\
6 / 6\end{array}$ & $\begin{array}{l}+2.50-1.0 \times 35 \\
+3.0-1.0 \times 135 \\
-1.0 \\
-1.5 \\
-0.5 \times 35 \\
-0.5 \times 0 \\
\text { Plano } \\
\text { Plano }\end{array}$ & $\begin{array}{r}+2 \\
+2 \\
0 \\
0 \\
0 \\
0 \\
0 \\
0\end{array}$ & $\begin{array}{l}\text { Atrophy } \\
\text { Atrophy } \\
\text { Atrophy } \\
\text { Atrophy } \\
\text { Surface wrinkling } \\
\text { Surface wrinkling } \\
\text { Broadened peri- } \\
\text { macular reflexes }\end{array}$ & $\begin{array}{l}\text { In all quadrants } \\
\text { In all quadrants } \\
\text { In all quadrants } \\
\text { In all quadrants } \\
\text { Very sparse } \\
\text { Very sparse } \\
\text { None } \\
\text { None }\end{array}$ \\
\hline \multirow{2}{*}{$\begin{array}{l}\text { Patient, } \\
\text { age } \\
\text { (years) }\end{array}$} & \multirow[b]{2}{*}{ Eye } & \multirow[b]{2}{*}{$\begin{array}{l}\text { Colour } \\
\text { vision }\end{array}$} & \multirow[b]{2}{*}{$\begin{array}{l}E R G \\
\text { rod b wave }\end{array}$} & \multirow{2}{*}{$\begin{array}{l}\text { Mixed } \\
\text { rod/cone } \\
b \text { wave } \\
(\mu V)\end{array}$} & \multicolumn{2}{|l|}{$30 \mathrm{~Hz}$ flicker } \\
\hline & & & & & $\begin{array}{l}\text { Amplitude } \\
(\mu V)\end{array}$ & $\begin{array}{l}\text { Implicit time } \\
(\mathrm{ms})\end{array}$ \\
\hline $\begin{array}{l}\text { II-8, } 76 \\
\text { II-10, } 59 \\
\text { III-2, } 34 \\
\text { IV-1, } 4\end{array}$ & $\begin{array}{l}\mathbf{R} \\
\mathbf{L} \\
\mathbf{R} \\
\mathbf{L} \\
\mathbf{R} \\
\mathbf{L} \\
\mathbf{R} \\
\mathbf{L}\end{array}$ & $\begin{array}{l}\text { Tritan defect } \\
\text { Tritan defect } \\
\text { NA } \\
\text { NA } \\
\text { Normal } \\
\text { Normal } \\
\text { Normal } \\
\text { Normal }\end{array}$ & $\begin{array}{l}\text { NR } \\
\text { NR } \\
\text { NR } \\
\text { NR } \\
\text { NR } \\
\text { NR } \\
\text { NA } \\
\text { NA }\end{array}$ & $\begin{array}{l}\text { NR } \\
\text { NR } \\
\text { NR } \\
\text { NR } \\
83 \\
93 \\
\text { NA } \\
\text { NA }\end{array}$ & $\begin{array}{l}\text { NR } \\
\text { NR } \\
\text { NR } \\
\text { NR } \\
90 \\
76 \\
\text { NA } \\
\text { NA }\end{array}$ & $\begin{array}{l}- \\
- \\
- \\
\overline{67} \\
67 \\
- \\
-\end{array}$ \\
\hline
\end{tabular}

^Following the grading of Fishman et al. ${ }^{13} \mathrm{NR}=$ non-recordable, NA=not available. ERG normal ranges (5th through 95th percentile) are $117-272 \mu \mathrm{V}$ for rod b wave, $292-622 \mu \mathrm{V}$ for scotopic mixed rod/cone b waves, $75-179 \mu \mathrm{V}$ for $30 \mathrm{~Hz}$ flicker amplitudes, and $58-63 \mathrm{~ms}$ for $30 \mathrm{~Hz}$ flicker latencies, respectively.
Figure 7 Detection of the 8 base pair deletion in exon 5 of the rhodopsin gene by gel electrophoresis of the DNA. Following PCR amplification, DNA fragments of patients II-8 (lane 2), III-2 (lane 3), IV-1 (lane 5), person III-4 (lane 4), and two non-related male controls (lanes 1 and 6 ) were analysed. Note the numerous shifts in the electrophoretic mobility of the three patients' DNA fragments. The two bands at the bottom (marked with arrows) correspond to double stranded DNA, while all others represent single stranded PCR fragments. $M=$ molecular weight marker.

\section{Discussion}

We studied five members of a family in which an $8 \mathrm{bp}$ deletion of the rhodopsin gene is cosegregating with the clinical expression of retinitis pigmentosa in persons heterozygous for the gene defect, whereas one person homozygous for the wild type allele is not clinically affected. In addition, there is consecutive transmission of the

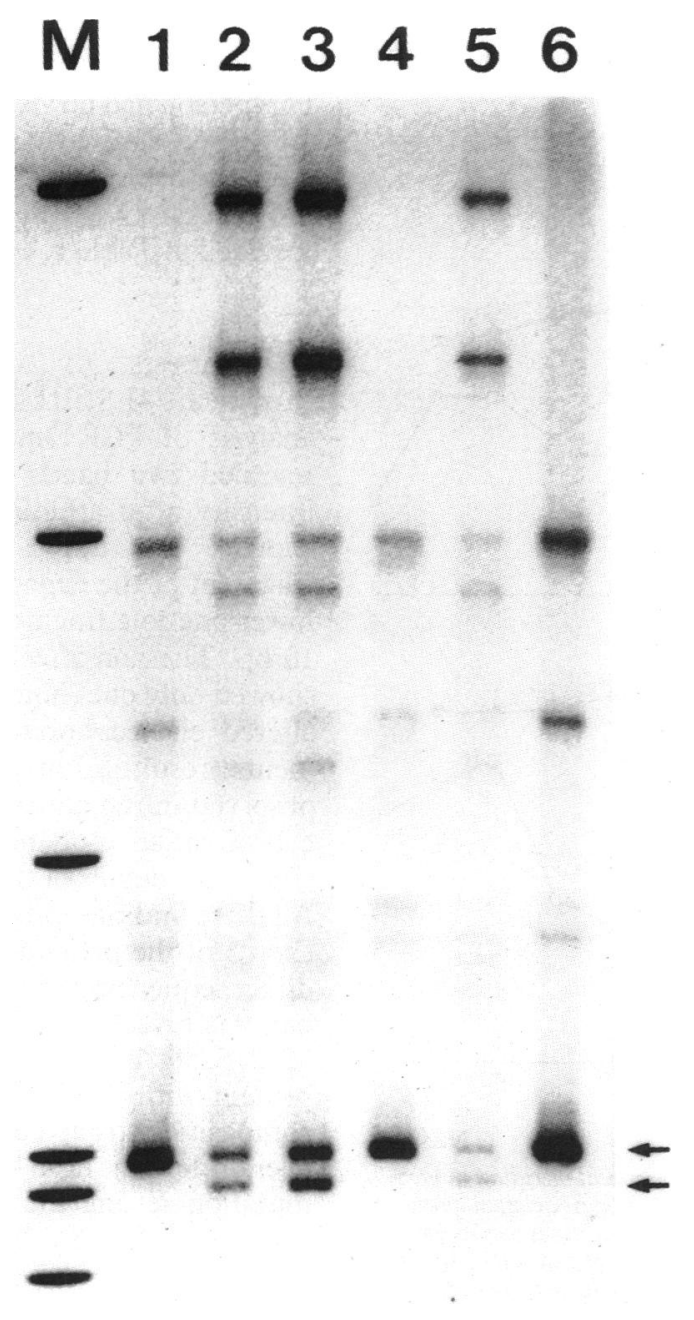

disease through at least four generations. These data strongly suggest that this mutation is causative for autosomal dominantly inherited retinitis pigmentosa, like a variety of rhodopsin mutations found thus far.

There are some characteristics in this form of adRP, which distinguish it from phenotypes of other mutations located at the $c$ terminal end of rhodopsin. Night vision impairment does not occur before the late teens. Likewise, in this pedigree there is late onset of visual field impairment with reasonable remaining field islands even in older individuals. Cone function is well maintained, even at a stage when the rod ERG is non-recordable. While these findings may be present in some other adRP families with various rhodopsin mutations, they are not common in patients with point mutations in codon $347 .^{7-9}$ Individuals with proline 347 leucine mutations, ${ }^{78}$ as well as patients with a proline 347 arginine' or a proline 347 serine mutation (Apfelstedt-Sylla et al, unpublished observation), tend to have early onset of night blindness and visual field loss, and nonrecordable ERGs even at younger ages.

On the other hand, Jacobson et a ${ }^{10}$ reported a family with a stop codon mutation at the $c$ terminal end of rhodopsin (glu 344) which demonstrates late onset and mild disease roughly comparable to the findings in our adRP family. Substantial differences between the families, however, concern rod function. No ERG rod responses could be detected in a 34-year-old individual with the $8 \mathrm{bp}$ deletion, while in patients with the glu 344 mutation of comparable age, Jacobson et al found only moderately reduced rod b waves. On two colour dark adapted threshold perimetry, rod sensitivity in these probands was measurable at most loci of the visual field, whereas in our patient III-2, rod mediated thresholds to the $500 \mathrm{~nm}$ stimulus could only be shown in the outer periphery. However, rod sensitivity loss in probands of both genotypes seems to be most prominent in the pericentral regions, and in a 44-year-old individual with glu 344 mutation at a more advanced stage of disease, only cone mediated thresholds are revealed. Cone function in younger individuals of both genotypes is well preserved, as shown by normal ERG cone amplitudes at only slightly increased implicit times, and by two colour threshold perimetry. So it cannot be concluded from these data whether different degenerative patterns are operating in both genotypes or whether the different findings rather reflect differences in onset or stage of the same pathogenetic process.

In the RP family reported here, the mutation found should result in a significant alteration of the amino acid composition at the $c$ terminal end of rhodopsin, and in the molecule which is one amino acid longer than the wild type (see Fig 8). Nine 'new' amino acids appear; one negatively charged residue (341 glu) is lost, and one positively charged appears ( $347 \mathrm{arg}$ ). The effects of these alterations on rhodopsin function are not clear.

Phosphorylation of light activated rhodopsin by rhodopsin kinase and subsequent binding of arrestin to phosphorylated rhodopsin terminate 
codons $\quad 340 \quad 341342343 \quad 344345 \quad 346 \quad 347 \quad 348$

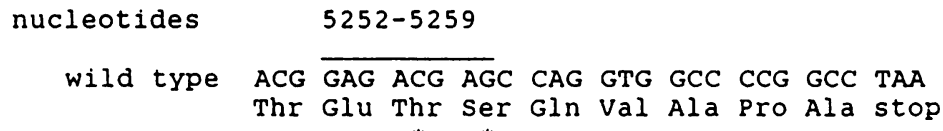

8 bp deletion ACG CCA GGT GGC CCC GGC CTA AGA CCT GCC TAG Thr pro Gly Gly pro Gly Leu Arg pro Ala stop

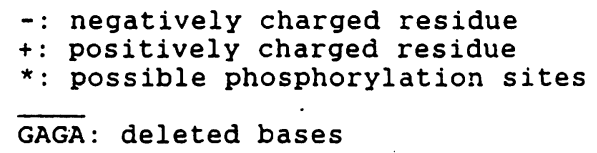

Figure 8 Eight base pair deletion in the human rhodopsin gene. Nucleotide and amino acid sequences for the wild types, and for the mutant genes and proteins, respectively. rhodopsin's activation of transducin and thereby quench the phototransduction process (for review, see Hargrave and $\mathrm{McDowell}^{17}$ ). Rhodopsin kinase phosphorylates serine and threonine residues at the $c$ terminal sequence of rhodopsin..$^{18}$ Out of the seven threonines and serines within codons $344-343$, only two are removed in the mutant molecule. Furthermore, it has been shown that not the $c$ terminal end but the third cytoplasmic loop of rhodopsin is crucial for rhodopsin kinase binding, ${ }^{19}$ and that rhodopsin kinase apparently tolerates some variety of amino acid sequence surrounding its substrates - that is, the threonines and serines, without impairment of its activity..$^{20}$ From these data it does not seem very likely that the mutation in this family has a strong effect on the efficacy of rhodopsin phosphorylation.

There are hints from tissue cell culture experiments, that some rhodopsin mutants may lead to disturbed transport of synthesised molecules to the plasma membrane, but this apparently does not hold for c terminal mutants pro 347 leu and glu 344 stop. $^{21}$ The 8 bp mutant displayed in this adRP family has to be constructed and tested to resolve the question of whether inefficient rhodopsin transport may be a cause of $\mathrm{RP}$ in this genotype.

Interestingly, the last two residues of the mutant rhodopsin molecule in our family are identical with those of the wild type - that is, there is a proline next to the final residue. As mentioned above, point mutations at codon 347 resulting in the loss of proline are associated with relatively severe clinical disease. One might speculate that the presence of a proline residue at the rhodopsin c terminal end has an effect on determining clinical severity, but this is in contrast to the mild phenotype displayed in the family with the stop codon mutation at codon 344 reported by Jacobson et al. ${ }^{10}$

At the present time, one certainly has to be cautious in drawing conclusions concerning phenotypical characteristics and disease processes in various genotypes. Our knowledge may expand when larger numbers of individuals can be tested clinically, and when in vitro experiments lead to better understanding of , the functional defects at the molecular and cellular level caused by alterations of the rhodopsin molecule.

Supported by grants Ru 457/1-1, Zr 1/7-1, and Ga 210/5-2 of the German Research Council (DFG).

1 Inglehearn CF, Keen J, Bashir R, Jay M, Fitzke F, Bird AC, et al. A completed screen for mutations of the rhodopsin gene in a panel of patients with autosomal dominant retinitis pigmentosa. Hum Mol Genet 1992; 1: 41-5.

2 Dryja TP, Hahn LB, Cowley GS, McGee TL, Berson EL. Mutation spectrum of the rhodopsin gene among patients with autosomal dominant retinitis pigmentosa. Proc Natl Acad Sci USA 1991; 88: 9370-4.

3 Bunge S, Wedemann H, David D, Terwillinger DJ, AulehlaScholz C, Sammans C, et al. Molecular analysis and genetic (chap mapping of the rhodopsin gene in families with autosomal dominant retinitis pigmentosa. (Submitted for publication)

4 Sheffield VC, Fishman GA, Beck JS, Limura AE, Stone EM. Identification of novel rhodopsin mutations associated with retinitis pigmentosa using GC-clamped denaturing gel electrophoresis. Am 7 Hum Genet 1991; 49: 699-706.

5 Sung C-H, Davenport CM, Hennessey JC, Maumenee IH, Jacobson SG, Heckenlively JR, et al. Rhodopsin mutations in autosomal dominant retinitis pigmentosa. Proc Natl Acad Sci USA 1991; 88: 6481-5.

6 Horn M, Humphries P, Kunisch M, Marchese C, ApfelstedtSylla E, Fugi L, et al. Deletions in exon 5 of the human thodopsin gene causing shift in the reading frame and autosomal dominant retinitis pigmentosa. Hum Genet 1992; 90: 255-7.

7 Berson EL, Rosner B, Sandberg MA, Weigel-DiFranco C, Dryja TP. Ocular findings in patients with autosomal Dryja TP. Ocular findings in patients with autosomal dominant retinitis pigmentosa and rhodopsin,

8 Apfelstedt-Sylla E, Kunisch M, Horn M, Ruether K, Gal A, Zrenner E. Diffuse loss of rod function in autosomal dominant retinitis pigmentosa with pro-347-leu mutation of rhodopsin. German f Ophthalmol 1992; 1: 319-27.

9 Niemeyer G, Trueb P, Schinzel A, Gal A. Clinical and ERG data in a family with autosomal dominant RP and Pro-347Arg mutation in the rhodopsin gene. Doc Ophthalmol 1992; 79: 303-11.

10 Jacobson SG, Kemp CM, Sung C-H, Nathans J. Retinal function and rhodopsin levels in autosomal dominant function and rhodopsin levels in autosomal dominant
retinitis pigmentosa with rhodopsin mutations. Am $\mathcal{f}$ retinitis pigmentosa with rh
Ophthalmol 1991; 112: 256-71.

11 Keen TJ, Lester DH, Inglehearn CF, Curtis A, Bhattacharya SS. Rapid detection of single base mismatches as heteroduplexes on hydrolink gels. Trends Genet 1991; 7: 5 .

12 Fishman GA, Alexander KR, Anderson RJ. Autosomal dominant retinitis pigmentosa: a method of classification. Arch Ophthalmol 1985; 103: 366-74.

13 Massof RW, Finkelstein D. Rod sensitivity relative to cone sensitivity in retinitis pigmentosa. Invest Ophthalmol Vis $S \mathrm{ci}$ 1979; 18: 263-72.

14 Dawson WW, Trick GL, Litzkow C. Improved electrode for electroretinography. Invest Ophthalmol Vis Sci 1979; 18: 988-91.

15 Marmor MF, Arden GB, Nilsson SEG, Zrenner E. Standard for clinical electroretinography. Arch Ophthalmol 1989; 107: $816-9$.

16 Massof RW, Finkelstein D. Two forms of autosomal dominant primary retinitis pigmentosa. Doc Ophthalmol 1981; 51: 289-346.

17 Hargrave PA, McDowell JH. Rhodopsin and phototransduction: a model system of $\mathrm{G}$ protein-linked receptors. FASEB f 1992; 6: 2323-31.

18 Sibley DR, Benovic JL, Caron MG, Lefkowitz RJ. Regulation of transmembrane signaling receptor phosphorylation. Cell 1987; 48: 913-22.

19 Palczewski K, Buczylko J, Kaplan MW, Polans AS, Crabb JW. Mechanisms of rhodopsin kinase activation. $\mathcal{f}$ Biol Chem 1991; 266: 12949-55.

20 Palczewski K, Arendt A, McDowell JH, Hargrave PA. Substrate recognition determinants for rhodopsin kinase: studies with synthetic peptides, polyanions and polycations. Biochemistry 1989; 28: 8764-70.

21 Sung C-H, Schneider BG, Agarwal N, Papermaster, DS, Nathans J. Functional heterogeneity of mutant rhodopsins responsible for autosomal dominant retinitis pigmentosa. Proc Natl Acad Sci USA 1991; 88: 8840-4. 